dealing more freely with cases which involve interference with the peritoneum. The brilliant results obtained by Mr. Banks of Liverpool, and Mr. Spanton of Hanley, in dealing with inguinal hernix, led me to undertake the operation just described, and Mr. Spencer of York has performed a similar operation with like success.

Of course the number of cases in which one would operate would be limited to those in which mechanical support had failed to give relief.

Leeds.

\section{COMPLETE SUPPRESSION OF SALIVA AFTER MUMPS.}

\section{BY A. ST. C. BUXTON.}

COMPLETE suppression of saliva in both parotids and both submaxillaries is of extremely rare occurrence. A case has, however, quite recently come under my care, the features of which were as follows.

A lady of over middle age, while in the country, contracted mumps. As soon as the acute inflammation of the salivary glands had subsided, and all pain and swelling had disappeared, she returned to town, and I was called in to see her. She spoke with great difficulty, and was forced to sip water at very short intervals in order to be able to speak at all. She told me that ever since the pain in the parotids and and submaxillaries had vanished her mouth had remained persistently quite dry.

On examination I found her tongue, gums, cheeks, palate, and pharynx - in fact as much as it was possible to see of the mouth and throat-in a fearfully dried up state. The tongue was thickly coated with a tough brown fur, which was horn-like. So hard was it that on striking it gently with a metal probe a distinct sound as of tapping the cover of a book with a cedar pencil was produced. The rest of the interior of the mouth was also extremely hard, and she experienced great stiffness in opening and closing the jaws. No swelling or tenderness on pressure existed about the salivary glands, and the orifices of Stenson's and Wharton's ducts were plainly seen. It is needless to say that she retained no sense of taste. She complained of the heat felt in the mouth, but the temperature was quite normal. Her sleep was greatly disturbed at night, and she awoke at short intervals with the most intense longing for cold water ; but drinking afforded no relief. It is worthy of notice that for some three or four years she has been affected with paralysis agitans, both limbs of the right side being very shaky. She enjoys otherwise excellent general health, and, notwithstanding the trembling in the right leg, is able to walk well, and takes plenty of exercise out of doors. There was a great deal of difficulty in feeding her, for she abso. lutely refused milk and beef-tea, and the effort necessary to swallow jelly and other semi-solid food was very great. I prescribed gargles of potassic chlorate, and ordered glycerine to be applied locally to the interior of the mouth and surface of the tongue. I ordered also an infusion of lifty grains of jaborandi to be taken daily for four days. Although the glycerine afforded some slight relief to the mouth by its mechanical effect as a lubricator, there was positively no effect produced on the salivary glands. Copious perspiration (from the jaborandi) took place, and left her feeling very weak. I therefore abandoned that drug, and substituted mercuric iodide dissolved in excess of potassic iodide. I gave large doses for ten days with no result beyond the production of a feeling of malaise. It was evident that something must be done soon to excite the flow of saliva, for the patient had been in this condition for nearly three weeks, and was in the lowest depths of despair and misery. The next step which I took therefore was the application of a continuous current of electricity generated by a 30-cell battery (pint cells) of the Leclanché type. I introduced a very fine silver probe into Stenson's duct on one side, and pushed it gently on until I met with obstinate resistance to further entrance. The probe had then entered the duct about an inch. My assistant held the positive electrode firmly to the nape of the neck, while I cautiously applied the negative pole to the free end of the probe. I instantly noticed a contraction of the fibres of the buccinator, but as no pain resulted I fixed the wire to the probe and allowed the passage of the current to continue for ten minutes. While the probe was in the duet a thick white liquid oozed from the orifice. It looked something like pus. On removal of the probe a single drop of clear saliva followed it. Thinking that it was just within the bounds of possibility that small abscess had existed somewhere about the duct and had been overlooked, and the probe had simply opened it and so cleared the obstruction to the flow of saliva into the mouth, I determined to thoroughly explore the other Stenson's duct and both Wharton's ducts before applying the current again. I passed the probe into all three remaining ducts as far as possible, removed it, compressed and squeezed the parts, but no pus followed. I repeated this again, but without finding a trace of pus. I then applied the current as before, with precisely the same result as in the first instance. I had the satisfaction of seeing four drops of saliva, one at the orifice of each duct. I visited my patient an hour afterwards, and a gentle flow of saliva was discernible from each duct. For three days the quantity steadily increased, without any further use of the current, and at the end of that time almost the normal amount was being poured out. The mucous membrane lining the mouth and the tongue was rapidly resuming its natural appearance. I have not seen my patient since, but I received a letter two days later stating that she had greatly improved; that the tongue was feeling quite comfortable, and that she was able to taste. A somewhat similar case is mentioned in the London Medical Record, 1877. The suppression of saliva resulted on that occasion from tonsillitis, and the flow was restored by stimulation by continuous current "frequently reversed." I did not reverse my current, preferring to submit the glands to the continued action of the negative pole. I find no mention of the condition in any medical work in which $I$ have searched, includ. ing Quain's Dictionary. of Medicine.

The Grove, W.

\section{ON A CASE OF}

\section{LABIO-GLOSSO-PHARYNGEAL PARALYSIS OCCURRING AT THE AGE OF} TWENTY-THREE YEARS.

\section{BY A. CHAMPNEYS CLARKE, L.K. Q.C.P.I., \&c.}

ON Nov. 13th, 1882, I was sent for to see Mrs. B-C, aged twenty-three years, wife of a coal miner. I was informed that she had always enjoyed good health, had borne one healthy child, and was now six months advanced in pregnancy. The previous evening, while shoveling coals into the coal-house, standing at the time in the snow, she had been seized with what was described as a sort of stroke. I found her suffering from paralysis of the left side of the face and left arm; articulation was imperfect owing to paralysis of the left half of the tongue, which when protruded was drawn towards the right side of the mouth. She gradually recovered from the facial paralysis, and in a great measure the use of her left arm, only complaining of its being weak. On February 11th I was again sent for to see Mrs. B she was said to have had another stroke. On arrival I found she had just been delivered of a healthy child, after a short and easy labour. She was completely unable to articulate or swallow, the tongue lay immovable on the floor of the mouth behind the teeth, hollowed in the centre; she could not close her lips completely, and the saliva dribbled from the sides of the mouth. The patient, an intelligent woman, complained (by signs) of great pain in the neck and throat, the muscles of which were contracted. She was at first fed through a tube, but disliking this means she was spoon fed, the spoon being introduced well back. She made a rapid convalescence from her confinement, and at the end of a week could swallow with considerable difficulty, placing the food (oruel and beef-tea) well back in her mouth and throwing the head back. The stiffness passed off, and she can now (March 21st) take fluid and semi-solid food fairly well. She is able to go about her household duties, but the tongue still remains paralysed, though by a great effort she can raise it as far as the edges of the teeth. She can close the lips at will, but when not called upon to do so the mouth hangs open and the saliva dribbles from the edges. She cannot articulate a single word, nor any letter in which the tongue has to be used.

The points of interest in this case are, I believe, the hitherto unknown occurrence of glosso-pharyngeal paralysis at so early 